\title{
The application of psychoeducation to families of schizophrenia patients
}

\author{
Débora Sales Nóbrega ${ }^{1}$; Maria Suely Sales da Nóbrega*2; Fabiane Gonçalves $^{3}$ \\ 1. Bachelor's degree in Psychology from the Faculty of Humanities - Olinda - Brazil \\ 2. Bachelor's degree in clinical psychology from the Faculty of Humanities of Olinda- Brazil \\ 3. Master's degree in Cognitive Psychology from the Federal University of Pernambuco - Brazil
}

E-mail adresses: deborasalespsi@gmail.com (Débora Sales Nóbrega), suelisales2008@hotmail.com (Maria Suely Sales da Nóbrega), fabianemsg@facho.br (Fabiane Gonçalves).

${ }^{*}$ Corresponding author

\section{To cite this article:}

Nóbrega, D.S.; Nóbrega, M.S.S.; Gonçalves, F. The application of psychoeducation to families of schizophrenia patients. International Journal of Sciences. Vol. 2, No. 2, 2021, pp. 18-23. ISSN 2763-5392.

Received: 08 10, 2021; Accepted: 08 11, 2021; Published: 09 06, 2021

\begin{abstract}
This scientific article aimed to understand how psychoeducation can contribute to the treatment of patients with schizophrenia, from the theoretical perspective of Cognitive Behavioral Therapy (CBT). The study was based on scientific articles found in books and on the Google Scholar platform, through the descriptors: Cognitive behavioral therapy; CBT and schizophrenia; Psychoeducation and schizophrenia. A clinical case report was also made based on the application of psychoeducation directed both to the schizophrenic family and to itself. Therefore, it showed the need for further studies on the subject, since few studies were found that spoke about these contents, therefore, the efficacy of psychoeducation for patient autonomy was demonstrated.
\end{abstract}

Keywords: Psychoeducation. Family. Schizophrenia.

\section{Introduction}

This scientific article brings in its content aspects related to the process of psychoeducation so that families of people with schizophrenia can develop a better relationship with their loved ones in suffering. This process aims at a more comprehensive and humane treatment to facilitate the bond between family members and the patient.

Schizophrenia has as a basic characteristic some symptoms: delirium, hallucination and negative and positive thoughts. Within this symptomatology we can establish numerous strategies for Cognitive Behavioral Therapy (CBT). Psychoeducation is shown as one of these strategies by which we can perform an effective treatment for various psychopathologies, not being different with schizophrenia.

The first impact the family receives is the diagnosis. Either because of the little knowledge about it, or the acceptance of having to live with the pathology for the rest of your life, or the numerous cases we see of neglect and abandonment. The fantasy that the life of that suffering individual will be getting worse seems quite evident in the initial understanding of family members.

Therefore, it is necessary to carry out an initial work with family members, showing them what schizophrenia is about. In order to make this possible, it is necessary to perform psychoeducation. In order to develop a better thought and understanding about what they will find if they are not as directed by the mental health team. In addition to also realizing all the positive aspects that will be found when conducting the treatment of mental illness correctly.

Therefore, this article aims to understand how psychoeducation in the family can contribute to the treatment of patients with schizophrenia, developing a look within the theoretical prism of Cognitive Behavioral Therapy (CBT).

\subsection{Conception of cognitive behavioral theory (CBT)}

Cognitive Behavioral Therapy can be conceptualized as a psychotherapy worked in the cognitive orientation model or as a combination of techniques aimed at promoting alterations both at the cognitive and behavioral level, besides referring to a range of more than twenty approaches belonging to the Cognitive and Behavioral model (KNAPP; BECK, 2008; KNAPP, 2004). From there follows the name "Cognitive Behavioral Therapy". 
As founder of Cognitive Therapy, Aaron Beck, he worked initially applying this theoretical model to patients who had depression disorder, intervening especially in the change of distorted or unrealistic thoughts, which negatively interfered with the feeling or behavior of their patients (KNAPP; BECK, 2008).

In this sense, from the beginning of this approach, it is perceived a great importance to the quality of thoughts in the assertive conduct of the individual. It can also be noted the inevitable change in feeling, after all, if the subject can transform his cognitive perception about some event, what he feels will also be transformed. In this panorama we will see that this triad: thought, feeling and behavior are interrelational, that is, interfere with each other. Therefore, when it comes to the need to modify a conduct, we can act both by the bias of thought and of feeling.

Over the course of interventions, demands for psychiatric disorders met Beck, such as anxiety and phobia disorders, suicide, panic syndrome, personality disorders, substance abuse disorders and then more schizophrenia, using protocols similar to those used in interventions in patients with depression (KNAPP; BECK, 2008). In this sense, the logic remained the same: to act on the distortions of thoughts arising from the symptomatology of mental illness.

The way each person sees reality will determine how they will feel and behave (KNAPP; BECK, 2008). Based on this principle, the change in the patient's perception becomes the great challenge of the therapeutic process. As the individual realizes that his belief in a given episode is in dismay with reality, he begins to see that there may be a different way of seeing the world or seeing oneself in the world.

\section{2 principles of $\mathrm{CBT}$}

As the basis of CBT is to correct and restructure the patterns of unrealistic thoughts, conscious or not, besides proposing some strategies to make emotions more positive, thoughts have gained more and more emphasis for this psychological approach, as they are at the beginning of the process of patient beliefs (KNAPP; BECK, 2008; KNAPP, 2004). Thought is shown as the main access to beliefs. If its validity is understood as true the subject can take possession of such content as being something absolute and consistent with his own reality.

Bringing these spontaneous thoughts to the fore to be reflected and analyzed, the patient appropriates what has surrounded his thought and interfering in his beliefs and sensations. The focus of CBT is precisely on correcting such misadjusted thoughts in order to confront them with reality, which causes as a consequence in the modification of the subject's beliefs (KNAPP, 2004).

To these quick and spontaneous thoughts, which produce instantaneous interpretation we call "automatic thoughts", their nature differs from reflexive thinking or free association and to avoid them one must be trained (KNAPP;
BECK, 2008). Through its spontaneous characteristic, automatic thinking continues to take on the beliefs of the individual, and may corrupt them if it is distorted. Soon, the feeling undergoes a change and begins to intensify its suffering.

If we enter into the origins of such distorted automatic thoughts, we will reach what is called 'schemes' or 'core beliefs', which are longer-lasting cognitive organizations and their action allows us to create new information, modeling the way the individual thinks (CLARCK et al 1999 apud KNAPP; BECK, 2008). So, we begin to understand how a person's set of beliefs is organized. The beginning of the dysfunctional chain takes place through an erroneous perception that takes place. Such information being assimilated as true will influence the others.

This time, if we want to know where such covert thoughts come from, we can get from the in-depth investigation that allows us to come into contact with the schemes, that is, the core beliefs. From this, the intense importance that CBT gives to thoughts, after all discovering its origins, it is possible to create strategies that contribute to transform the behavior of the individual.

Thus, CBT works in order to reorganize the perception of the individual through the modification of thoughts and consequently the deeper beliefs presented by him. From the reflections, the subject is led to evaluate the contents of the thoughts that surround him and that insist on re-emerging. The proposal is to reduce or eliminate their symptoms and replace dis adaptive resources with more functional strategies and behaviors, which have repercussions on feelings and attitudes aimed at a positive reality.

Therefore, in CBT it is natural to provide the patient and his family with resources and teach them how to use when necessary. This mechanism is called psychoeducation (KNAPP; BECK, 2008). It is perceived that in this way the process matures more quickly, since its recurrence will create an understanding, on the part of those who use it, of the ability to control aspects of understanding of what is happening to the other. The person becomes his own therapist as he is trained about the techniques and ways to approach the challenges. Family members also begin to obtain such knowledge in order to follow the evolution of the being that is in need of this care.

This psychoeducation process also has the beneficial effect of accelerating the psychopathological picture of the patient, since, as therapeutic follow-up extends to the outside, it is in the family or social environment that practices exercised in consultation will undergo changes in their behavioral patterns. All this tends to be made possible by the deconstruction of distorted beliefs and their consequent resignifications.

Thus, we can reflect, that the great impasse that surrounds a person's life is the poor construction of the beliefs that he processes, because by distorting reality we harm future constructions. Here we have a possibility of explaining the formation of psychopathologies in the CBT approach: a sequence of distorted beliefs of reality. The 
breaking of such a sequence and its functional modifications is where the psychotherapist's interventions in CBT point out.

\section{2.family and schizophrenia}

According to the Diagnostic and Statistical Manual of Mental Disorders (DSM-V), within the chapter "Spectrum of schizophrenia and other psychotic disorders" there are five essential characteristics for defining psychotic disorders: delusions, hallucinations, disorganized thinking (speech), grossly disorganized or abnormal motor behavior (including catatonia), negative symptoms. Also, according to this manual, one of the criteria used to diagnose schizophrenia disorder is when one or more of these five domains of the characteristics previously listed are confirmed, being present for a period of at least one month.

\subsection{Symptoms of the schizophrenia spectrum}

Within the psychopathological parameter we can identify some characteristic symptoms of the schizophrenia spectrum. Among them we can find the presence of: hallucinations, delusions, disorganized thinking, disorganized motor behavior and negative symptoms.

Hallucinations are of the order of perception, that is, of the senses, not requiring external stimulation, being involuntary and the person develops them clearly, as is the case of auditory hallucinations, the subject clearly hears voices (American Psychiatric Association, 2014).

Also, according to this manual, hallucinations must take place differently from those that occurred when falling asleep (hymenagogic) or in awakening (hypnopompics), because this is considered normal experiences; besides these, in certain cultural contexts, hallucinations can maintain relationships with phenomena of religious experience. Therefore, such psychic mechanisms are structured according to the senses. The auditory and visual forms seem to be the most recurrent.

Delusions are fixed beliefs, which do not change when in the light of contradicted evidence, and may have several themes (persecutory, reference, somatic, of greatness) (American Psychiatric Association, 2014). In the persecutions delusions the person believes that he will suffer some injury or harassment by someone, some organization or even some group; in the delusions of reference, the subject believes that someone is commenting something about him, sometimes it is enough for another person to make some gesture, which such an individual takes for himself; the delusions of grandeur make the person believe that he possesses exceptional abilities, that he is rich or famous personality and delirium. The individual believes that the other person is in love with him.

It is perceived, in view of this, that the nature of delusions is of express order of thought. That is, the person thinks with conviction that the content of his imagination is, in fact, happening. Even another person possessing a valid argument to counter such a belief still does not seem to be enough.

As for disorganized thoughts, we noticed a disconnect between the sequence of ideas, usually desiring what was asked and what was answered, making the speech incomprehensible, that is, substantially impairing communication (American Psychiatric Association, 2014). It is necessary to emphasize this aspect: communication must be substantially committed to such disconnections of thought in so that it is stated that it is a symptom of disorganization in thought.

In disorganized or abnormal motor behavior we have to have several forms of expressions, which can develop as a child behavior or to the point of performing unpredictable movements, which brings several damages to the individual's life, since he has difficulties in performing routine activities 014).

Also, according to the manual, there may be a decrease in the behavioral activity of the individual, remaining rigid, inappropriate or without verbal and motor responses; in addition to repetitive (stereotyped) movements, fixed gaze, faces and echoes in speech (American Psychiatric Association, 2014). As for negative symptoms, we see that two symptoms predominate in schizophrenia: decreased emotional expression (reduction of facial emotional expressions, eye contact, intonation) and avolia (decrease in self-initiated activities that have a purpose) (American Psychiatric Association, 2014).

It is observed these two types of phenomena we can think of an individual who when he speaks gives little or no emotional emphasis through the absence of gestural movements. In addition, you can spend several time intervals sitting, demonstrating disinterest in activities, especially social activities. Here, such a trait seems to lead you to an enormous difficulty in socializing.

\subsection{Types of schizophrenia}

According to the International Classification of Diseases (ICD-10) regarding the types of schizophrenia we can find several ways to manifest, which allows us to divide it into: paranoid; heberfrenics; catatonic; undifferentiated; post-schizophrenic depression; residual; simple; other schizophrenia; unspecified schizophrenia.

Although there are all these types of manifestations of schizophrenia, we intend only to stop ourselves in the explanations of three of these types, that is: paranoid, heberfrenics and simple. This choice is due to the emphasis on interventions within these three psychopathological types, and there is no need to lengthen dealing with the other types.

Knowing that, the first guy we're going to meet is the paranoid. As the International Classification of Diseases (ICD-10) brings, in this type it can be understood that it is the predominance of a delusional thought, where the related theme turns to persecution or conspiracy, besides sometimes being accompanied by symptoms of hallucination. Given this, it is possible to remember that the individual whose suffering comes from this pathological typology, has distorted beliefs 
or perceptions of reality, since the recurring themes are persecution and conspiracy. That is, the person who is not suspicious of several people, when not everyone around her, this ends up leaving her quite scared and confused, especially at the time of the outbreak.

According to the International Classification of Diseases (ICD-10) another type of schizophrenia is what is called disorganized or hebephrenic, where disorganized or unpredictable behaviors follow, as well as thoughts, in addition to what has some mannerisms, that is, stereotyped movements, differing from paranoid, as to the symptoms being constant, not manifesting in an outbreak. Due to these symptoms, we can see how difficult it is to live with people affected by this type of schizophrenia, since it is not uncommon to find them on the streets living as beggars.

Also, according to the ICD-10 in simple schizophrenia, there is a progression of psychotic symptoms, affecting the quality of thoughts, in addition to a fall in the intellective potential, starting discreetly, although easily perceived by a mental health professional through dialogue and evaluation, however, when treated, including by the drug route, a slope of the pathology is perceived. Reflecting on these explanations it is possible to imagine that within the family this pathology can go unnoticed. Entities can understand that such conducts of this individual are due to the peculiar way of being, that is, of expressing oneself.

\subsection{Psychoeducation in the schizophrenic family}

According to Beck et al (2010) long-term goals must be established together with the patient, where it is generally divided into: forming relationships; getting a job; living independently. Still according to these authors, when the symptoms of delusions and hallucinations hinder such goals we must deal directly with these symptoms.

There will be patients whose normal techniques will suffice, because they have a good premorbid history and a higher level of cognitive functioning, however those individuals who do not have such a favorable prognosis will have to use different techniques, and the therapist should be more directive and clearer in his explanations (BECK et al 2010). It is understood, therefore, that this differentiation of choice of techniques should be based on the neurocognitive parameter of each patient. This is because we know that each type of schizophrenia is consolidated with a different intensity, and may be more or less severe and thus causing a greater or lesser amount of damage to the social life of each person.

Many of the adaptive behaviors of people who have schizophrenia swerve from delusions. The intensity of beliefs in these symptoms are indicators of prognosis, so the greater the conviction that the individual has about a given situation, the more difficult the deconstruction of such belief will be given (BECK et al 2010). Despite this, there are patients who say they oscillate in the convictions of their thoughts; however, it is also known that many are controlled by delusional interpretations (STRAUSS, 1969 apud BECK et al 2010).

According to Beck et al (2010) interventions in the face of delusions are boosted through the identification of the erroneous interpretations that the individual makes of the experiences lived, influenced by the symptom in question and reinforced by compensatory behaviors. Thus, he begins to understand what actually hinders his inferences about the facts and how this distorted process makes his life difficult.

It is necessary to describe the egocentric orientation contained in the underlying beliefs of the patient, identifying self-referential ideas and events and relying on these contents is that unrealistic orientation is formed about oneself from external attention, other people or beings, generating perceptions of themselves as vulnerable or superior (BECK et al 2010). Also, according to these authors, patients also use random events and some coincidences as reinforcers of their beliefs. Therefore, you may believe that a rain or wind was a deliberate action of someone or some supernatural force in their intention.

Given this, after this survey of the understanding of beliefs is that it becomes possible to intervene through the appropriation of dysfunctional thoughts, simultaneously performing the intensity of the conviction presented by the subject, that is, how much he believes in what appears in his thought. The intensity of the conviction will give us parameters to evaluate the validity of the interventions performed.

It can be brought activities to be learned in consultation, ask questions and enable family members attitudes of supervision and follow-up of such activities, since the individual affected by delusional symptoms will exercise essentially in his social routine. Therefore, a notebook for recording automatic thoughts will be of great value, since it will allow the subject himself to evaluate the flow of thoughts and their most frequent contents that day and what encouraged such contents to come to the fore.

Together with the record of unadaptive thoughts we can use the construction of new, more adjusted and positive thoughts. This procedure is relevant that it be performed under the supervision of some family member, especially at the beginning of the construction of this routine. This is to avoid new negative convictions departing from the same misfit belief and under interference from delusional symptoms. However, gradually the migration to attitudes of greater autonomy is one of the objectives, after all the result of the process is that the individual is, himself, his therapist.

Making the most convinced substitution of dysfunctional thoughts it will be possible to observe more functional behaviors, because the feelings of this individual will undergo positive transformations. Therefore, perceiving a change of attitude in these individuals will also be possible to identify a perceptual modification of the facts and of oney, besides, of course, a more constructive feeling.

If we analyze the functions of these interventions, we will perceive a focus focused on the exercise of reality. As the person appropriates his thoughts, feelings, attitudes and rationally analyzes his beliefs and the convictions he has of 
these, he becomes increasingly in contact with reality, with concrete constructions. It moves away from illusions while it is linked to the real and the functional.

\section{Psychoeducation in the schizophrenic family - clinical case}

Psychoeducational interventions were designed with the patient regarding the primary symptoms of schizophrenia and for each of them we will establish some general strategies to work in partnership with his family. Given that the symptoms of schizophrenia end up making the individual insecure and dependent. Therefore, it will not be uncommon to find situations in line with these two aspects, such as unemployment issues, isolation, difficulty in relating, studying.

The case in which we will bring to the discussion is based on an individual who has a military father, whose name we will treat as D. S. This father presents in his family a genetic history of mental disorder. D. S.'s mother is a psychologist and claims that her pregnancy was quiet. Her delivery was normal, but she had some complications at birth. D. S. presented different behaviors since childhood, such as fears, crying, insecurity. He had encopresis (resistance to defecating) and nocturnal enuresis (not being able to control urine). It took him to get out of the diapers, performing his physiological needs in the toilet only at the age of 8 . Also, around that same age began the process of leaving conducts such as sucking pacifiers. He presented difficulty in speaking and in the elaboration of some words. He always studied in private school and at the end of high school began his physical therapy college. In addition, he took an English course where he received a certificate of best student. At the age of 19, he began his first outbreaks when he joined the Brazilian navy. Feeling pressured by the circumstances that moved him in the corporation. He went to the naval base of Rio Grande do Norte / Natal. Even returning to the naval base in Recife continued with the psychotic crises, arguing that colleagues were speaking ill of him and that he was being persecuted, including some television programs spoke ill of him. He had hallucinations and delusions. He was evaluated by the psychiatrist of the naval hospital who removed him from work, with justification the diagnosis of paranoid schizophrenia (F20) and depression (F30). It achieved significant improvement after the onset of antipsychotic medications and mood stabilizers such as Olanzapine, Ketros and Carbolithium. Currently D. S. is stabilized, has a life with autonomy, has good social interaction, has good coexistence.

To do so, the family had to understand the real meaning of the pathology. Therefore, it was necessary to re-signify the meaning of mental illness, even so that family members could better manage the challenging situations of the person in suffering, which results in the reduction of hospitalizations.

The family learned that it should stimulate D. S. in communication, make more meetings with friends and relatives, perform tours, showing him the importance of the social. Gradually this process allows the creation of a routine. Walk, go to the gym, read, establish interaction activities with people, without overload. Here the subject feels human, performing activities like all other people perform.

As the subject resumes his activities, he also takes note of his responsibilities. Thus, it will be no different in educating you for the daily commitment in the correct administration of your medications, clarifying your duty in the involvement of your continuous treatment process and the importance of not forgetting the use of your medications for your healthy development.

Family members should keep in mind that on the other side there is a being that is in suffering, so it is important not to confront when in crisis, because if we do so we will not be developing a human relationship, stimulating autonomy on the other, but imposing our wills on it. When we show empathy, tenderness, affection, we were able to establish a greater bond, stimulating in the subject a feeling of acceptance. In this respect, it should be emphasized that family members should not be permissive, they need to be loving, but establishing limits for certain situations that may provoke undue behavior. This is because certain families, afraid of the individual developing crises, give in to the whims that end up stimulating dysfunctional behaviors.

\section{Conclusion}

For all the above, we understand that the psychoeducation applied to the family can contribute to the advancement of the treatment of patients with schizophrenia, through the theoretical conception of Cognitive Behavioral Therapy (CBT).

This scientific production contributed to a better understanding of the subject who suffers, minimizing his difficulties in the relationship with the other; how you deal with your psychotic symptoms; in the way you work with your distorted beliefs and thoughts. All these contributions can be made possible the instant a good psychoeducation is carried out with your family.

Through the more human look at the being with schizophrenia and also for his family it is possible to resignify the concept present in the psychic sphere of the family. This process enables the achievement of the acceptance of the diagnosis by both the family and the patient, which can immediately promote more assertive attitudes in coping with the pathology in question.

Autonomy is the objective to be achieved by the patient. This can be facilitated or not by family members as they exercise, together with the patient, activities that corroborate with a better accountability of their attitudes. Thus, starting with simpler tasks such as taking medications at the correct times, achieving a regular positive frequency, can stimulate improvement of the patient's self-esteem, which can increase their self-confidence to account for increasingly complex activities.

Therefore, this scientific article contributed in a theoretical and practical way to minimize and better deal with 
psychotic symptoms through psychoeducation. Therefore, the benefits are expanded both for the family and for the patient himself, who is better understood in his pain.

\section{References}

[1] KNAPP, P \& BECK, A.T. - Fundamentos, modelos conceituais, aplicações e pesquisa da terapia cognitiva. Revista Brasileira de Psiquiatria. 2008. Disponível em: https://www.scielo.br/scielo.php?pid=S151644462008000600 002\&script=sci_abstract\&tlng=pt. Acesso em: 06/12/2020.

[2] KNAPP, P. Princípios da Terapia Cognitiva. In: Knapp, P (org). Terapia Cognitivo Comportamental na prática psiquiátrica. Porto Alegre: Artes Médicas, 2004.

[3] AMERICAN PSYCHIATRIC ASSOCIATION. Manual diagnostico de transtornos mentais: DSM-V. Porto alegre: Artmed, 2014.

[4] OMS - Classificação de Transtornos Mentais e de Comportamento da CID-10: Descrições Clínicas e Diretrizes Diagnósticas. Porto Alegre: Artes Médicas, 1997.

[5] BECK, A. T; RECTOR, A. N; STOLAR, N; GRANT, P. Terapia Cognitiva da Esquizofrenia. Trad. Ronaldo Cataldo Costa; consultoria, supervisão e revisão técnica Paulo Knapp - Porto Alegra: Artmed, 2010. 